Pragmatics 17:2.183-201 (2007)

International Pragmatics Association

DOI: 10.1075/prag.17.2.01bel

\title{
SENTENCE-INITIAL AND AND BUT IN ACADEMIC WRITING
}

\author{
David Bell
}

\begin{abstract}
Prescriptivists have long proscribed sentence-initial And (SIA), and sentence-initial But (SIB). However, SIA and SIB are increasingly used in newspapers and style guides have softened strictures against their use. Moreover, SIA and SIB are amongst the most frequently occurring sentence-initial connectives within their respective semantic groups of additives and contrastives. Given their use despite prohibitions, this paper examines the patterns of occurrence and function of SIA and SIB in academic writing. The data come from 1 million words of academic prose: 11 journals representing science, social science, and humanities. The data confirm the findings of Biber et al. (1999) that while coordinator and is more frequent in academic prose than but, SIA is much less frequent than SIB. The data also reveal a marked difference between low SIA and SIB occurrences in scientific writing and much higher occurrences in social science and humanities. Plus, SIA is the preferred additive connective compared with moreover, furthermore, and in addition, etc., and SIB is the second most preferred contrastive connective after however. SIA and SIB in academic writing function in three very similar ways: (i) to mark off a discourse unit by indicating the last item on a list, (ii) to indicate the development of an argument, and (iii) to indicate a discontinuity or shift with a previous discourse unit. Whereas the most common function of SIA is that of indicating the last item on a list, the most common use of SIB is in the development of arguments. SIA and SIB perform special functions that the alternatives of asyndetic or "zero" coordination, the use of similar discourse markers: moreover, furthermore, in addition, and however, respectively, or intrasentential coordination cannot perform. These special functions are derived from their particular semantic meanings, their role as coordinating conjunctions, and their reduced phonological prominence. These features allow SIA and SIB to preface a wider range of lexicogrammatical units such as interrogatives, stance adverbs and other discourse connectives and to create a tighter form of cohesion. It is these special features of cohesion rather than a move to colloquiality which are held to explain the occurrence of SIA and SIB in academic writing.
\end{abstract}

Keywords: Sentence-initial connectives; Additives; Contrastives; Cancellatives; Coordination; Conjunction; Asyndetic or "zero" coordination; Intersentential/intrasentential coordination; Colloquiality; Prescription; Phonological prominence.

\section{Introduction}

Prescriptivist grammarians have long proscribed the use of sentence-initial And, hereafter SIA, and sentence-initial But, hereafter SIB. However, SIA and SIB are in increasing use in newspaper writing (Cotter 2003), and an increasing number of style guides have softened their strictures against SIA and SIB (Cunningham and Greene 2002; Raimes 2002). What is more, the evidence from this present study suggests that in academic writing, SIA and SIB are amongst the most frequently occurring sentenceinitial connectives within their respective semantic groups of additives and contrastives. Given the relative abundance of their occurrences despite their proscription, the aim of 
this paper is to examine both the frequency and function of SIA and SIB in academic writing.

With regard to frequency, I confirm the findings of Biber et al. (1999) that while coordinator and is more frequent in academic prose than but, SIA is much less frequent than SIB. My data also show a marked difference in the use of SIA and SIB across different genres of academic writing with SIA and SIB being far more prevalent in humanities journals. Furthermore, I show that SIA, when compared with other additive connectives such as moreover, furthermore, in addition, etc., is the most frequently occurring additive marker in academic writing, while SIB is the second most preferred so-called "contrastive" connective after however.

With regard to function, I argue that both SIA and SIB in academic writing function in three very similar ways: (i) to mark off a discourse unit by indicating the last item on a list; (ii) to indicate the development of an argument; and (iii) to indicate a discontinuity or shift with a previous discourse unit. Whereas the most common function of SIA is that of indicating the last item on a list, the most common use of SIB is in the development of arguments. Further, I argue that SIA and SIB perform special functions that the alternatives of asyndetic or "zero" coordination, the use of discourse markers that share their broad semantic function: Moreover, furthermore, in addition, and however, respectively, or intrasentential coordination cannot perform. These special functions are derived from their particular semantic meanings, their role as coordinating conjunctions, and their reduced phonological prominence. These features allow SIA and SIB to preface a wider range of lexico-grammatical units such as interrogatives, stance adverbs and other discourse connectives and to create a tighter cohesive fit. It is these special features of cohesion rather than a move to colloquiality, i.e. the informality characteristic of spoken language or of writing used to create the effect of conversation, which are held to explain the occurrence of SIA and SIB in academic writing.

After detailing my data sources, I discuss SIA and SIB in turn with respect to three perspectives: Previous research, an analysis of the functions of SIA and SIB in my academic writing corpus, and a discussion of the specific properties of SIA and SIB with respect to the options of "zero" or asyndetic coordination, intrasentential coordination, and the use of other discourse connectives that fulfill a similar semantic function.

\section{Data}

The data consist of over one million words of academic prose taken from 11 academic journals representing science, social science, and the humanities (see figure 1 for a full list of journals.) 
Figure 1: Frequency of SIA and SIB according to Academic Journal

\begin{tabular}{|c|c|c|c|c|}
\hline & JOURNAL & WORDS & AND & BUT \\
\hline 1 & Sports Engineering & 109,435 & 0 & 0 \\
\hline 2 & Blood & 92.322 & 0 & 0 \\
\hline 3 & Analytical Chemistry & 81,959 & 1 & 4 \\
\hline 4 & Applied Psycholinguistics & 101,000 & 3 & 1 \\
\hline 5 & $\begin{array}{l}\text { Family Economics and Nutrition } \\
\text { Review }\end{array}$ & 97,981 & 10 & 7 \\
\hline 6 & Sociology of Health and Illness & 92,599 & 6 & 31 \\
\hline 7 & $\begin{array}{l}\text { North American Journal of } \\
\text { Economics and Finance }\end{array}$ & 104,316 & 20 & 69 \\
\hline 8 & $\begin{array}{l}\begin{array}{l}\text { Medicine, Health Care and } \\
\text { Philosophy }\end{array} \\
\end{array}$ & 102,163 & 34 & 73 \\
\hline 9 & History and Memory & 100,761 & 38 & 85 \\
\hline 10 & Anthropoetics & 101,564 & 31 & 105 \\
\hline 11 & Philosophy and Rhetoric & 100.763 & 35 & 114 \\
\hline & & $\mathbf{1 , 0 8 4 , 8 6 3}$ & 178 & 489 \\
\hline
\end{tabular}

Because the focus here is on the use of SIA and SIB in academic discourse, I have excluded occurrences of SIA and SIB in academic writing from other modes such as in transcripts of conversations or in quotes from fiction.

\section{Sentence-initial And}

I begin by surveying previous studies on SIA starting with a historical perspective on SIA and then going on to review the work of Halliday and Hasan (1976) and Schiffrin (1986, 1987) and then look at how Schiffrin's analysis especially has been applied to literature and newspapers. ${ }^{1}$ Building on these studies, I examine the functional uses of SIA in academic writing according to how it marks the end of a discourse unit, the continuation of a discourse unit, and a shift to a new discourse unit. Finally, I try to understand why SIA is used in preference to "zero" coordination, other additive discourse connectives, and to conventional intra-sentential coordination.

\subsection{Previous studies of SIA}

Dorgeloh (2004) has argued that present day proscriptions against SIA can be traced back to changes in preferences for discourse structure, a move from paratactic to subordinate conjunction, most particularly in the domain of scientific writing with its evolving standards of objectivity and argumentative structure. (See also Bazerman 1988) As the nature of the scientific experiment began to change in the mid-seventeenth century, Dorgeloh argues, SIA "became associated with older more narrative, and hence

1 There is, of course, a vast literature and on-going debate on the semantics of coordinator and. See Schiffrin (1986) and Blakemore and Carston (2005) for reviews of this literature. 
less professional style and thus became increasingly stigmatized" (2004: 1770). Dorgeloh suggests that the banishment of SIA in academic scientific writing presaged the more general prohibition against SIA in most other written language. (See also Huttar 2002 for a diachronic perspective on SIA in literature).

Halliday and Hasan's (1976) focus on SIA is part of their larger discussion of conjunction as one cohesive device in the larger concept of cohesion. They describe coordination as an intrasentential structural device while conjunction is seen a cohesive device that relates sentences. In their taxonomy of conjuncts, SIA is described as signaling an additive relationship between sentences while but is described as an adversative. Although they acknowledge that conjunction is derived from coordination, they argue that "Conjunction ... is not simply coordination extended so as to operate between sentences" (238). Halliday and Hasan note that one difference between coordinate and and conjunctive and is that coordinate and can link any number of items, whereas conjunctive and links pairs of sentences. However, Halliday and Hasan do acknowledge that sets of sentences similar to coordination do exist especially if they share parallel structure. They argue that the following example, although punctuated as sentences, is not really interpretable as consisting of separate sentences, but more a set of coordinate clauses (235).

1. 'At the end of three yards I shall repeat them - for fear of your forgetting them. At the end of four, I shall say goodbye. And at the end of five, I shall go!'

Although Halliday and Hasan suggest that such occurrences are infrequent, it should be noted that their corpus consists solely of "Alice in Wonderland." As we shall see later, SIA as signaling the last item on a list is the commonest use of SIA in academic writing. And indeed the use of and to signal the last item in a series of complex instructions as in (1) above is quite frequent in science and social science journals.

Halliday and Hasan also distinguish a further use of SIA, which they suggest comes closest to its structural function as a coordinator, which they call " "next in a series (of things to be said)"' (236). The example they give is Alice's interrogation of Humpty Dumpty about the meaning of Jabberwocky, in which Alice precedes each new question with And. They also suggest that another example would be "a series of points all contributing to one general argument." In this function, Halliday and Hasan argue that And retains some of the retrospective or retrojective effect, i.e. "projecting backwards' (236) that and has as a coordinator. Here, SIA signals not the last item on a list but rather the continuation of an ongoing list of items, and as we shall see, I will argue that this use of SIA to develop arguments is the most frequent use of SIA in humanities journals.

However, apart from these cases cited above where cohesive And operates similarly to coordinator and, Halliday and Hasan claim that the typical context for SIA is one where "there is a total, or almost total shift in the participants from one sentence to the next, and yet the two sentences are very definitely part of a text" (235) as in (2). Another common context in narrative fiction for this shift is at the boundary of dialogue and narrative as in (3) below.

2. He heaved the rock aside with all his strength. And there in the recesses of a deep hollow lay a glittering heap of treasure. 
3. 'While you're refreshing yourself,' said the Queen, 'I'll just take the measurements.' And she took a ribbon out of her pocket, marked in inches.

Schiffrin (1986, 1987, 2006) examines utterance and turn-initial and in conversation. She argues that and has two roles in talk: An ideational role where it coordinates idea units - what she calls a "discourse coordinator" role, and an interactional or pragmatic or discourse marker role where it continues a speaker's action, i.e. marking the speaker's upcoming utterance as a continuation of the content and structure of an interaction, and these two functions most often occur simultaneously (1987: 128). As a marker of functionally differentiated idea units, the presence of and signals that the speaker identifies an upcoming unit as structurally coordinated or equivalent to a prior unit. In this way, and can differentiate among other things background/foreground in narrative, support and position in arguments and explanations, and can also differentiate discourse topics. However, Schiffrin stresses that identifying the nature of these units “depends on textual information beyond and itself” (1987: 141).

Summarizing Halliday and Hasan (1976) and Schiffrin (1986, 1987, 2006), SIA can be seen as bracketing discourse units, continuing discourse units, or signaling a shift between discourse units; and what determines the discourse function of these signaled discourse units is constructed by the interaction of the linguistic properties of and with the discourse slot in which it occurs. I now look at how this framework has been used by several writers to examine the use of SIA in written language.

Sotirova (2004), using the works of D.H. Lawrence, has argued that SIA, as well as other connectives, are used by Lawrence to signal perspectival shifts in free indirect style: "it seems that Lawrence creatively engaged with a feature of oral narration to use it structurally for the manipulation of viewpoints" (227). Huttar (2002) has examined the use of both discourse-initial and (DIA) and SIA in poetry. Huttar argues that DIA is often used to establish an imagined context already in progress or imagined prior events from which the present utterance is understood to continue. An extremely common form of DIA is that of a question addressed in response to an implied interlocutor's statement and often expressing surprise at the previous implied statement. Huttar notes that in Julian's (1892) A Dictionary of Hymnology, out of 99 hymns that begin with DIA, 64 of them are questions. Here, we might conjecture that DIA appears to be coordinating the upcoming discourse with some prior unit, which we may take to be, in a religious context, the believer's ongoing meditation on the almighty.

Cotter (2003) examined the use of SIA and SIB in newspapers over a one hundred year period. She used a 100,000-word corpus of newspaper articles - a mixture of local and national syndicated articles, general news, and feature articles - published between 1900 and 1995 in a small town newspaper in Northern California. Over this period, she noted an increasing occurrence of SIA/B and concurrent decline in temporal connectives. Among other factors, Cotter argues that these connectives help to create local and global coherence in news narratives, introduce new speakers and ideas, and link a series of short paragraphs. Cotter sees this increasing use of SIA/B as indicative of a historical shift from more text-centered to more reader-centered prose. When the reporter's purpose is primarily text-centered such as in front-page news stories SIA/B are avoided in favor of more accepted rhetorical and communicative devices in written language. In more reader-centered texts such as op-ed pieces, where a more perspectival style is considered desirable, or in "light" news, where the stylistic conventions of hard 
news are less strict, there is more use of what Cotter describes as "cooperation seeking mechanisms of speech" of which SIA/B are taken to belong.

Dorgeloh (2004) looked at SIA in a corpus of British English made up of LOB (Lancaster-Oslo/Bergen, 1961) and FLOB (Freiburg Lancaster-Oslo/Bergen, 1991). Her data actually show a decline in the use of SIA in both academic and newspaper writing. However, her sample was comparatively small to generalize from. Nevertheless, from her qualitative analysis she concludes that in written Modern English, SIA, where it does occur, marks functional shifts on a more global level of discourse. However, since modern prescriptive grammar associates SIA with colloquiality, i.e. the informality characteristic of conversation, Dorgeloh finds that discourse coordination is now standardly achieved by "zero". (1777).

What emerges from the above discussion is a tripartite function of SIA. First, SIA marks off discourse units by its ability to signal the upcoming last item on a list; second, SIA signals continuation of a discourse thread; and third SIA can signal a functional shift in the discourse. In the next section, I examine the use of SIA in academic discourse according to these three functions.

\subsection{Sentence-initial And in academic discourse}

Out of the 178 tokens of SIA in my corpus, 17 occurred in combination with discourse markers, of which 13 occurred in combination with yet and one each with hence, so, therefore, and on the other hand. In such combinations, it is hard to know what role SIA plays beyond the semantic relationship conveyed by the discourse marker it prefaces. Excluding these examples, in the remaining 161 tokens, 90 occurred in symmetrical, i.e. listing uses and 71 were asymmetrical, i.e. signaling continuation or shift. The occurrence of symmetrical and asymmetrical SIA varies according to genre. Scientific and social science journals had relatively more symmetric occurrences of SIA while humanities journals had a higher ratio of asymmetric SIA.

In its symmetric use, SIA is used to indicate the last item on a list. This is more clearly seen where there are three or more items on the list (52 tokens) as opposed to two-item lists (38 tokens). Lists are often marked explicitly by an organizational sentence (italicized), which announces the items on the list as in (4) below.

4. Three meal-pattern categories were created based on their ability to provide meaningful comparison of eating behaviors: Consistent, moderately consistent, and inconsistent. (My italics). These categories are mutually exclusive and include all possible combinations of eating occasions. Respondents with a consistent meal pattern $(n=538)$ consumed two or three meals (plus or minus snacks) on all 3 days of reported intake. Those with a moderately consistent meal pattern $(n=726$ consumed two or three meals (plus or minus snacks) on 2 of the 3 days of reported intake. And respondents with an inconsistent meal pattern ( $\mathrm{n}=46$ consumed only one meal (plus or minus snacks) or snacks only on all 3 days of reported intake. (Family Economics and Nutrition Review)

SIA may also combine together with explicit enumerators as in (5). 
5. First, she views this long repetitive process as a "discomfort with Ranke, the father" (no explicit mention of Oedipus, though). Second, it gives her "an eerie feeling of having heard the same claims over and over only expressed in different ways." And third, facing the many and contradictory opinions of historians, she sighs: "At times our frustration is so great that we think we can never make sense...." How true. (History and Memory)

The notion of the list and the equality of the items on the list are often reinforced by parallel structure (underlined phrases) as in (6).

6. Both a speaker and a hearer can be expected to have "common knowledge." We know that generally, if a restaurant puts certain utensils on the table, then normally these would be the kinds of utensils suited to eating the kind of food served. And we know that eating soup with a fork is not only unusual and socially inappropriate, but also highly inefficient. (Philosophy and Rhetoric)

In some examples the elliptical privileges of intrasentential coordination and are carried over to intersentential connections as in (7).

7. The analysis in the current paper suggests that participants (doctors, nurses, patients) are not just as Berg indicates, taking organization into account, but that they are producing and reproducing organization. And, critically that they are not just producing an organization. (Sociology of Family Health).

In example (8) below, and both coordinates the items on a list of "possible sources of error" intrasententially, but also adds a further and more important item intersententially. (8) is also an example of how the last item on the list can be marked as the most important.

8. The possible sources of error with regard to these precision measurements (my italics) are retention time variation in both separation dimensions, signal-to-noise levels, injection volume reproducibility for both separation dimensions, and analyte-to-interference-peak height ratio. And foremost, the degree of peak overlap, that is, resolution, is another important source of error. (Analytical Chemistry)

With regard to asymmetric occurrences of SIA, the largest category of occurrences indicate the continuation or development of a discourse unit or what I will call in the context of academic writing, argumentative chains. An argumentative chain describes the way that arguments are derived from and build on prior arguments. This chaining effect is linguistically marked by topic development or the way that the comment or new information slot in $\mathrm{P}$ becomes the topic or given slot in $\mathrm{Q}$.

9. A small country in the Ricardian model, then, cannot lose from fragmentation so long as prices of final goods remain fixed. And fixity of prices has a certain plausibility if the rest-of-world is integrated, as noted above. (North American Economics and Finance) 
10. The ordinary person, needless to say, rarely shares this sinister and degrading conviction. Yet it remains possible, in the right circumstances, to convince people of their unhappiness by appealing to base motives like resentment. And resentment, in turn, demands an object. The consolidation of power requires, then, an external enemy, on whom the unhappiness of the ordinary person can be blamed. (Anthropoetics)

The element in the prior discourse may not be just locally adjacent but may be part of the larger global message of the previous discourse segment. Here, the previous message is often picked out by a demonstrative, especially in a cleft structure as (11) below.

11. Kracauer notes that when the grandmother stood in front of the camera "she was present for one second in the spatial continuum that presented itself to the lens. And it was this aspect and not the grandmother that was eternalized." (History and Memory)

A third broad use of SIA is in marking a discontinuity or shift in the discourse, most often marked by a movement away from an argumentative chain or thread to what is clearly an authorial comment on the previous discourse. The following examples illustrate some of the ways this shift can be realized. In (12), Q realizes what is speculative in P; in (21), Q contradicts the notion of the "end of history"; and in (13) and (14) Q is parenthetical to the main thrust of the discourse. ${ }^{2}$

12. Not much is left to respect. There remains only an old man to abuse. And this is exactly what awaits him, precisely as he celebrates his son's successfully concluded training. (Philosophy and Rhetoric)

13. La morale de cette histoire, as fables have it, is that like the Russian rulers who kept abolishing (the abolished) capital punishment from time to time, so at various times various authors, thinkers and jokers keep announcing the end of history. And this is certainly not the end of the story. (History and Memory)

14. They were not alone to dissent, and ever since discomfort and discord plagued the new historians' work and cogitations: Michelet criticized Ranke's theories, Guizot criticized Michelet, Thierry criticized Guizot and Mignet rejected all of the above. (And what kind of scientific discipline is that if each new generation of historians declares that the preceding one had it all wrong?) (History and Memory)

15. He still imagines that his suffering is unique and fails to identify, metaphorically, with the bull in the arena or the fish on the line. He wanders the streets. He talks to himself. He is like some medieval fool setting himself on itinerant display. (And Ellison indeed invokes "the Fool's Errand," as we have seen.) (Anthropoetics)

The parenthetical SIA sentences in (14) and (15) tend to consist of a formal rather than a substantive shift: In (14) the shift is from a declarative to interrogative, while in (15) the shift is similar to (12). There were also two examples of footnotes which begin with SIA, which may also be considered as parenthetical in a similar sense to (14) and (15).

2 Blakemore (2005) uses the term “and-parentheticals" to refer to a detached and conjunct inserted into a host structure. I use the term parenthetical in its more explicit sense. 
The use of SIA to mark these kinds of shifts especially where an authorial perspective is introduced appear to be limited in academic writing. The major use of SIA is to bracket off discourse units by signaling the last item on a list, where the items on the list may consist of instructions, arguments, or stages in a process. It is here that SIA is acting most like a coordinating conjunction. The other main use of SIA in this corpus is to signal the continuation of an argument or what I have called argument chains.

\subsection{Why use sentence-initial And in academic discourse?}

So far I have looked at the functional work SIA does, but why, given the strictures against sentence-initial and, is SIA used in this way rather than "zero", i.e. asyndetic conjunction or other additives such as in addition, furthermore or moreover, or intrasentential and conjunction? No doubt there are stylistic choices and prescriptions at work here, but we can detect the syntactic, phonological, semantic and pragmatic features of SIA, which the other options do not offer, and so influence the choice of SIA.

In terms of SIA's syntactic privileges, there are two main structural categories which and colligates with but other additives do not. These are interrogatives and adverb phrases. Out of 178 tokens of SIA in the academic corpus, there are 15 instantiations of And + INTERROGATIVE as in example (16).

16. Since both expert knowledge and user knowledge are necessary in order to make rational decisions in technology, and in medicine in particular, how can they be obtained? And who should make the decisions? (Medicine, Health Care and Philosophy)

In the same corpus there are 149 tokens of moreover, 129 tokens of in addition and 80 tokens of furthermore, but there are no colligations with interrogatives. Similarly, unlike and, there were no colligations of in addition, furthermore or moreover with adverbial phrases in clause-initial position such as enumerators like secondly or finally, stance adverbs like critically as in (7) above and connectors like similarly, below.

17. A critical factor here seems to be the magnitude and nature of the economic reform process, in particular whether a candidate country is sufficiently reformed to join an existing union. And, similarly, whether existing members are reformed to an extent such that an outsider would be interested in joining. (North American Journal of Economics and Finance)

A further constraint on the interchangeability of and and other additive connectors is that the latter are far more semantically restricted in the nature of the additive relationship they signal. Blakemore (1987) has described furthermore and moreover as "strengthening connectives" in that they signal that the utterance following is providing further support for a previous claim. This suggests that they are less able to conjoin independent units of equal importance as in a list nor can they signal the last item on a list. What is more, they are not comfortable in argument chains, especially 
when the discourse segment SIA prefaces can be understood as a resultative, or in elaborative, contrastive and parenthetical relationships as exemplified in (12)-(15).

A further important feature of and and but is their phonological reduction compared with the greater intonational prominence of their corresponding discourse connectives moreover and however (Halliday and Hasan 1976). Whereas in addition, furthermore and moreover require a slight pause before a following word or phrase, often indicated by a comma, And is able to attach itself to a following word or phrase rather like a clitic. In the following example, moreover seems awkward because of the need for two substantial pauses at the beginning of the sentence - after moreover and again after this.

18. The great success of the play indicated that the public shared this view. "History and life are doomed to live it out in hate, in distrust, in mutual failure," commented Plumb. They are lost in timeless falsehood, bound by dreams of the past that may not have existed, and enslaved by their own lies about the future. And/?Moreover this, as the audience streamed out into the flashing neon lights of Broadway, seemed to have the force of truth. (History and Memory)

So far I have argued that And has certain syntactic, semantic and phonological features which similar additive discourse connectives do not have. However, SIA can be avoided by either omission, that is moving from syndetic to asyndetic conjunction, or in other words from And to "zero", or by making and intrasentential rather than sentence initial connection. With regard to "zero", SIA is clearly the marked option as Dorgeloh (2004) has suggested. Whereas, And can signal a wider set of relationships between sentences than in addition, furthermore or moreover, it cannot signal the array of relationships such as explanation, exemplification, reformulation etc, that asyndetic conjunction can (Carston 2002). ${ }^{3}$ The motivation for the use of SIA in academic writing may therefore stem from the kinds of listing relationships that asyndetic conjunction may fail or struggle to signal. In the following example, SIA signals the structure of the discourse in a way that "zero" does not.

19. What is the impact of a currency union on the real economy? The most recent empirical literature seems to offer a positive answer to this important question. For example, Rose and Engel (2000) have found that members of currency unions are more integrated than countries with their own currencies, as reflected in more trade and less volatile real exchange rates. And, in an attempt to quantify the effect of currency union on output, Frankel and Rose (2000) have estimated that every one percent increase in trade would raise income per capita by roughly one percent over twenty years.

The choice of SIA here may be motivated by the fact that the sentence is fronted by a non-finite adverbial clause. A default reading of this sentence without SIA may be to see it as a development of the argument in P, i.e. the findings of the research of Rose and Engel. The insertion of SIA may facilitate the reader's interpretation of $\mathrm{Q}$ as additional to, rather than a development of, $\mathrm{P}$, especially given the organizing idea of

3 Schiffrin (2006) places and on a scale of informativeness with "zero" to the left and the temporal marker then to the right. The scale increasingly specifies the relationship between discourse segments. 
the most recent empirical literature. Note that if the sentence had begun with the subject phrase Frankel and Rose (2000), there may have been less motivation to use SIA other than to signal the last item on the list.

A final option, of course, is to make and conform to its usual intrasentential conjunction. There seem to be two main reasons why this option is not taken in the case of SIA occurrences in this corpus. First, in the case of lists, the use of SIA simplifies the identification and processing of the list, especially where list items are complex. A frequent occurrence of SIA in this corpus is signaling the last item on a list of complex mathematical instructions as in (20) below.

20. To construct the PPF in three dimensions, I place the origin of Country A's PPF on the surface of Country B's PPF, T B Z B Z B 9. As a result of the shapes of the two PPFs, point Z A 9 of A's PPF traces out a duplicate of B's PPF: the triangle Z0 W $\mathrm{Z}-\mathrm{W} \mathrm{Z}+\mathrm{W}$. The bottom edge of A's PPF, Z A Z A 9 traces out the parallelogram $\mathrm{Z}$ W Z9 W Z0 W Z+W as its origin traverses T B Z B. And A's PPF itself becomes the topmost facet of the world PPF, the triangle $\mathrm{T} \mathrm{W} \mathrm{Z9} \mathrm{W} \mathrm{Z0} \mathrm{W}$. (North American Economics and Finance)

Second, with non-list SIA, the SIA option appears to be motivated by the need to separate out stages in argumentation. In both cases, decisions to use SIA appear to be motivated by the need to make the text more reader-friendly, although this is not to agree with prescriptivists that the occurrence of SIA in this corpus is evidence of colloquiality, that is the characteristic informality of spoken language or of writing used to create the effect of conversation.

The association of colloquiality with SIA may be better understood by Traugott's (1986) open/closed-field distinction between what she calls listing connectives and the notion of speaker involvement. A closed-field model refers to the way that spatio-temporal relations are anchored with regard to the speaker on the one hand and some final reference point on the other. An open-field model refers to the way that objects are ordered in one direction in an infinite set. Traugott identifies and as operating in a closed-field model and numerical connectives first, second, etc as operating in an open-field model. Traugott then suggests that the choice of open or closed-field connectives may reflect speaker involvement. Speaker involvement is the degree to which the speaker, based on speaker perspective, is implicitly involved in the construal of the connective relations (Pander Maat and Degand 2001). On this basis, we would expect numerals to be used as listing connectives in scientific academic writing in preference to SIA and SIA to be used more in humanities writing. The evidence here suggests that this is indeed the case.

\subsection{Conclusion}

I have argued that in academic writing SIA is used for three main purposes: (i) to shape text in the form of lists by indicating the last item on a list, (ii) to develop arguments by topic development, and (iii) to signal shifts in authorial perspective in terms of elaborative, contrastive and parenthetical comments on the previous discourse. By far the most important of these functions is that of the listing function. The use of SIA is not frequent in scientific texts, more so in the social sciences and common in 
humanities, and overall and is the preferred additive connective. The predominant use of SIA in scientific and social-science journals is that of a listing connective whereas in humanities SIA is used equally for listing and argument chaining. The motivation to use SIA springs from its greater syntactic and semantic range compared with similar additives in addition, furthermore or moreover. This may be in part due to its reduced phonological prominence (with respect to these other additives), which allows And to preface interrogatives and certain adverbs. With regard to "zero" or asyndetic conjunction, it was argued that despite the greater range of semantic relationships signaled by "zero", "zero" may not clearly signal the listing function that SIA clearly can. Furthermore, the use of SIA is also prompted by the need to simplify complex lists from the perspective of rendering text more reader-friendly and the need to both make independent and highlight certain propositions which might otherwise be obscured in a complex coordinated sentence. Rather than SIA being a mark of colloquiality in academic writing, it was argued that it could be seen as a mark of speaker involvement in the construal of connective relations, which is more characteristic of writing in the humanities.

\section{Sentence-initial But}

As has already been suggested, the proscriptions against SIB are far less strong than those against SIA and this in part explains the far greater occurrence of SIB in academic discourse. ${ }^{4}$ However, the strongest proscriptions against SIB appear to be in scientific journals with the three journals representing science in this corpus providing just 4 examples of SIB out of a total of 489.

Unlike SIA, studies of SIB are few. Although there has been a burgeoning number of studies of but: Blakemore $(2001,2002)$ from a relevance theoretic perspective; Thompson (2005) working in the framework of systemic functional linguistics; Umbach (2005) from the perspective of information structure; and Nemo (2006) from a construction-based perspective, none of these approaches distinguishes between the function of but as an intersentential conjunction and but as a sentenceinitial marker. The approach that more readily deals with but in sentence-initial position is the framework that treats SIB as a discourse marker. Discourse markers indicate relations between discourse segments, speech acts and discourse participation. According to Bell (1998) but as a cancellative discourse marker provides an instruction as to what aspect of information derivable from the prior discourse, $\mathrm{P}$, either globally or locally is to be canceled by the current message Q. An aspect of information is any piece of information, either explicit, or implicit in the form of an assumption or implication, which is derivable, though not necessarily derived, by the hearer analyst from the prior discourse. In this framework, SIB is seen as a discourse tool, which allows speakers to subtract potential unintended meanings away from existing intended meanings.

4 It is interesting to note that prescriptivist prohibitions on sentence-initial conjunction vary according to Quirk et al's (1985) gradient of coordinating and subordinating conjunctions. The most prohibitions apply to and and or, which Quirk et al. describe as more pure or "central coordinators"; there are fewer prohibitions on but; and moving towards the subordinating conjunction end of the scale, there are no restrictions on yet. 
I begin by showing how SIB operates in academic writing according to a similar tripartite function as SIA: By marking off idea units through its ability to coordinate ideas; as a device of argument development, and third as a way of shifting the topic domain. However, unlike SIA, I note that the most frequent use of SIB is for argument development. I then compare SIB with other coordination options: Asyndetic coordination, the use of other cancellative markers like however, and intrasentential coordination. I conclude that SIB shares with SIA similar syntactic and prosodic features that privilege SIB over however, but unlike SIA, "zero" coordination cannot be considered an option to SIB.

\subsection{Sentence-initial But in academic discourse}

Similar to the discussion of SIA, I will identify the function of SIB in three ways: (i) to coordinate idea units, (ii) to develop arguments, and (iii) to shift the topic domain. In my corpus, by far the most important function of SIB is to develop arguments.

Like SIA, SIB can use its coordination function to mark off idea units by adding the final element on a list. There were just a few examples of this use of SIB in the corpus. In these examples, SIB combines with a comparative or superlative, which allows a further element to be added to the previous set of arguments. In the examples below, this additive effect comes in paragraph-initial position in (21) and (22) and paragraph-internal position in (23) and (24).

21. I have tried to find a concrete image for this space in photography and films. In Camera Lucida it exists in the simple example Barthes gives to explain that reality and photography are intertwined by a special relationship, another sort of skin, which make photography belong to "that class of laminated objects whose two leaves cannot be separated without destroying them both: the window pane and the landscape."

But an even more pertinent example exists in the realm of film. (History and Memory)

22. People cannot make use of a technique unless the technique really works, and that it works at least to the extent it is believed to work. This is the second criterion. But there is one more thing to consider in a definition of usefulness. (Medicine, Health Care and Philosophy)

23. In fact, he indicates that we have to make the map as we proceed (that, even now, we are doing so). Certainly, this is at least in part necessary so that we can retrace our steps if required. But more important, our guide instructs us that it is the very making of the map that produces the territory we want to cover. (Philosophy and Rhetoric)

24. She eats food only from the right side of her dinner plate, does not notice anyone who approaches her from the left, etc. But these are not the worst things for Mary and her relatives. The worst thing is that Mary does not remember the persons that have been closest to her. (Medicine, Health Care and Philosophy)

It is not hard to see how this coordinating feature of but can also be exploited to bring about major shifts in the topic domain as in example (25) below. We would not expect such abrupt topic domain shifts in academic writing as we would expect in 
spoken casual conversation. Nevertheless, SIB can be used to achieve shifts in topic in academic writing as in (25) where SIB prefaces a meta-discoursal sign-post, in (26) where SIB signals the cancellation of the meta-discoursal proposition in the prior discourse, and in (27), and in (28) where SIB combines with a question in paragraphinitial position.

25. The second, I think more interesting, interpretation allows that Hegel escapes from a "specular" ideology, something we can "see through," but accuses him nevertheless of falling into a purely "linguistic" ideology, language pretending to be and do other than it is and does. But before taking up de Man's charges, I shall run through Hegel's account. (Philosophy and Rhetoric)

26. There can be various different kinds of use bases, and analyzing all of them is beyond the scope of this investigation. But one of the most important ones is that referred to as "common knowledge." (Philosophy and Rhetoric)

27. By way of contrast, if technical change takes place in a small open economy with given goods prices, it is the sector-bias that determines the factor price effect. And this is precisely what happens in the case considered by Arndt. But this still leaves the question of which of the two views is more relevant. (North American Journal of Economic and Finance)

28. Thus, in Schama's case (which has been chosen here to epitomize a wider phenomenon), Dead Certainties was not an isolated instance of mixing fact and fiction, as some reviewers believed, but an expression of a systematic application of this approach.

But is this fiction/faction genre really so new as it seems to some critics? (History and Memory)

However, the combination of SIB plus a question functions mainly in what is the largest use of SIB in academic writing and that is argument development. If SIA facilitates argument development by building on or adding to the argument structure, then SIB facilitates argument development by its canceling or refining the previous argument. It is beyond the scope of this paper to explore the many ways in which cancellation operates in terms of argument development, but I give examples of some of the main ways

29. After a few days Mary regains her ability to talk. But her speech has lost the usual inflection and tone, making a machine-like and dead impression. (Medicine, Health Care and Philosophy)

30. I am not suggesting that war equaled a pleasure trip. But it did introduce many German men (and some women), willingly or not, to new experiences, cultures, landscapes, foods and customs. (History and Memory)

31. The nature of design is partly revealed in the qualities of products. But it is also revealed in the processes of design thinking that lead to the creation of products. There is little agreement among practicing designers or design educators about what constitutes the precise pattern of the design process. (Philosophy and Rhetoric)

32. It is reasonable to infer that John ate the lobster. Of course, it is possible that in some actual case, John did not eat the lobster. But that would not be the normal 
order of events, judging from what we are told in the given text. (Philosophy and Rhetoric)

Example (29) is a classic case of cancellation where the Q segment refines the implied broader claim of normal speech ability made in P. Or put in another way, whereas SIA is an additive tool, SIB in this example can be seen as a subtractive tool in negotiating the meaning of Mary regaining her ability to talk. Example (30) operates very similarly to a disarmer by making a negative statement of intent in $\mathrm{P}$ and then canceling an aspect of that claim in Q. Note the use of the emphatic auxiliary and the concomitant intonation, a feature of this kind of cancellation. (31) is an example of the common use of SIB together with an additive, here also, as well as the parallel structure that accompanies these kinds of examples. Indeed, it seems that SIA could easily substitute for SIB in this example, but the author has preferred to achieve the coordination by implying a certain incompatibility between the qualities of products and the processes of design thinking as indications of the nature of design. While SIB performs the same coordination function as SIA, it adds extra contextual implications through the revelation of the author's thinking. (32) is an example of epistemic cancellation, which is a frequently used form of cancellation in academic writing: $\mathrm{P}$ makes a hypothetical claim which is canceled in Q.

It is certainly not surprising that SIB is so extensively used in humanities journals as a tool of argument development. Just as SIA is a tool for conveying speaker meaning by adding meaning onto meaning, SIB is a tool which allows speakers to subtract unintended meanings away from an existing meaning. As we have seen, SIB can also mark off idea units and signal shifts in the discourse in the same way as SIA but to a much lesser extent than its role developing arguments.

\subsection{Why use sentence-initial But in academic discourse?}

With regard to SIA, I examined the choice of SIA compared to "zero" or asyndetic coordination, other additives, and intrasentential and coordination. Likewise the choice of SIB can be compared with other cancellative markers and intrasentential coordination, but not with asyndetic coordination. As we saw earlier, there can exist a variety of relationships between discourse segments in asyndetic coordination but not one of cancellation.

Like SIA, the crucial feature of SIB, which distinguishes it from other cancellatives and especially however is its phonological reduction. It is this feature which helps explain why it can preface discourse markers, stance adverbs and interrogatives while however does not. There were 21 examples of SIB prefacing a discourse marker: in fact (4), on the other hand (3), indeed (2), at the same time, nonetheless, even so, still, above all, also, further, again, and then. In the 9 instances where however appeared with a discourse marker, it always occurred in the postposition. The markers that prefaced however were at the same time (3), instead (2), at the same time (3), again, in addition and in fact. However also appeared in post-position in the two occurrences with the enumerator first. There were 8 occurrences of SIB prefacing a stance adverb: more importantly, significantly, admittedly, ironically, paradoxically, most notably. Of the 6 occurrences where however appeared together with a stance adverb - equally (2), curiously, critically, importantly, however always 
occurred in post-position. Out of 489 occurrences of SIB there were 20 examples of SIB + INTERROGATIVE whereas out of 1114 occurrences of however there were only two examples of however + INTERROGATIVE or 1.84 occurrences of however + INTERROGATIVE per million words compared with 18.4 for SIB + INTERROGATIVE. So whereas, it is not impossible for however to preface an interrogative, it appears to be very infrequent.

Another area where SIB may be preferred to however is in reported speech, where the cancellation is attributed to a third party. So in (33) the cancellation signaled by $B u t$ is attributed to the senator in response to the judge while in (34) the But cancellation is attributed to Bitzer whose ideas are being reviewed.

33. And thereupon the judge instantly began arguing in favor of popular sovereignty, the right of the people to have slaves if they wanted them, and to exclude slavery if they wanted to do so. But, said a senator from Ohio, by the name of Chase, we more than suspect you do not mean that the people shall have the right to exclude slavery if they want to, and if you do mean it, accept an amendment expressly authorizing the people to exclude slavery. (Philosophy and Rhetoric)

34. Interestingly enough, Bitzer blames this on the new rhetoricians of the eighteenth century, not on twentieth-century theorists. But he notes such "universalizing" continues in statements like the following, found in the Report of the Committee on the Scope of Rhetoric and the Place of Rhetorical Studies in Higher Education published in The Prospect of Rhetoric (1971): "[rhetorical studies] include any human transaction in which symbols and/or systems of symbols influence values, attitudes, beliefs, and actions ...” (1971: 214). (Philosophy and Rhetoric)

The effect of using however in both these instantiations of SIB is to create at least an ambiguous reading in that the cancellation signaled by however is more likely to be attributed to the author of the article rather than to the senator or Bitzer respectively. The explanation for the preference of But here seems again to lie in its phonological reduction and its role as a coordinating conjunction.

Finally, the option of intrasentential coordination rather than SIB coordination seems to be determined by the same features that were discussed in terms of SIA. The SIB option appears to be motivated by the need to separate out and highlight stages in argumentation and the need to make the text more reader-friendly. As we have seen the SIB option appears to be far more readily available in academic writing than SIA because of the fewer strictures against SIB especially in humanities journals

\subsection{Conclusion}

I have shown that in academic writing SIB is used for the main purpose of argument development through the wide variety of cancellation that can be signaled in the current message. To a much lesser extent, SIB like SIA can shape text in the form of lists by indicating the last item on a list and also to signal shifts in the structure of the discourse. SIB is most frequent in humanities journals where it facilitates argument development by the way that it allows speakers to negotiate meaning by canceling unintended layers of meaning in the prior discourse. The motivation to use SIB like SIA comes from its greater syntactic privileges in sentence-initial position compared with however. This 
may be due to its function as a coordinating conjunction and its reduced phonological prominence with respect to however. In any case, SIB is more likely than however to preface interrogatives, stance adverbs, and discourse markers and to coordinate segments of reported speech.

\section{Conclusion}

In this paper, I hope to have shown that despite the strictures against sentence-initial And and to a lesser degree against sentence-initial But in academic writing, SIA and SIB occur frequently in academic writing and perform special functions that the alternatives of asyndetic coordination, discourse markers of a similar additive or cancellative function, or intrasentential coordination cannot perform. These special functions have been located in their role as coordinating conjunctions and their reduced phonological prominence together with their particular semantic meanings which allow them to function in sentence-initial position and to create a type of cohesion that other similar discourse markers cannot. The data confirms the greater proscriptions against SIA than SIB with SIB occurring almost 3 times as much as SIA. As we have seen, there is a marked variation in the use of SIA and SIB across different genres of academic writing with scientific writing holding the line on proscriptions against SIA and SIB while they are far more prevalent in humanities journals. In these journals, SIA is by far the most frequently used additive while SIB is second only to however as a cancellative. Both SIA and SIB function in three very similar ways: (i) to mark off a discourse unit by indicating the last item on a list, (ii) to indicate the development of an argument in a discourse unit, and (iii) to indicate a discontinuity or shift with a previous discourse unit. Whereas the most common function of SIA is that of indicating the last item on a list, the most common use of SIB is in the development of arguments.

This paper has looked at a small corpus of academic writing but, as can be seen, the way that SIA and SIB operate is complex. This complexity appears to support two broad conclusions. First, this complexity would appear to belie approaches which seek to explain the meaning of and and but solely in terms of inferential procedures and by using convenient introspected examples. What SIA and SIB indicate at any one time is as a result of an interplay between their semantic, syntactic and prosodic features and the discourse context in which they appear. This would appear to warrant an explanation of the instruction conveyed by SIA and SIB in the minimalist of terms as I have tried to capture by the notion of the cancellation of an aspect of information derivable from the prior discourse. Second, any explanation of the use of SIA and SIB in academic writing by recourse to notions of colloquiality and reader-friendly text, are only partial explanations. What we have seen here is that SIA and SIB provide special features of cohesion that alternative forms of coordination do not, and ultimately the flaunting of proscriptions against their use is likely to be because of the linguistic privileges they allow rather than from just stylistic choices.

\section{References}

Bazerman, Charles (1988) Shaping Written Knowledge: The Genre and Activity of the Experimental Article in Science. Madison: The University of Wisconsin Press. 
Bell, David M. (1998) Cancellative discourse markers: A core/periphery approach. Pragmatics 8.4: 515542.

Biber, Douglas et al. (1999) Longman Grammar of Spoken and Written English. Harlow, England: Longman.

Blakemore, Diane (1987) Semantic Constraints on Relevance. Oxford: Basil Blackwell.

Blakemore, Diane (2001) Indicators and procedures: Nevertheless and but. Journal of Linguistics 36.3: 463-48.

Blakemore, Diane (2002) Relevance and linguistic meaning: The Semantics and pragmatics of discourse markers. Cambridge: Cambridge University Press.

Blakemore, Diane (2005) and-parentheticals. Journal of Pragmatics 37: 1165-1181.

Blakemore, Diane, and Robyn Carston (2005) The pragmatics of sentential coordination with and. Lingua 115.4: 569-589.

Carston, Robyn (2002) Thoughts and utterances. The Pragmatics of Explicit Communication. Malden, MA: Blackwell.

Carston, Robyn, and Diane Blakemore (2005) Introduction to coordination: Syntax, semantics and pragmatics. Lingua 115.4: 353-358.

Cotter, Colleen (2003) Prescriptions and practice: Motivations behind changes in news discourse. Journal of Historical Pragmatics 4.1: 45-74.

Cunningham, Helen, and Brenda Greene (2002) The Business Style Handbook. Chicago: McGraw-Hill.

Dorgeloh, Heidrun (2004) Conjunction in sentence and discourse: Sentence initial and and discourse structure. Journal of Pragmatics 36.10: 1761-1779.

Halliday, M.A.K., and Ruqaiya Hasan (1976) Cohesion in English. London: Longman.

Huttar, Charles A. (2002) Introductory And as a device in poetry-making. Philological Quarterly 81.2: $139-57$.

Nemo, François (2006) Discourse particles as morphemes and as constructions. In Kerstin Fischer (ed.), Approaches to Discourse Particles. Amsterdam: Elsevier, pp.375-402.

Pander Maat, Henk, and Liesbeth Degand (2001) Scaling causal relations and connectives in terms of speaker involvement. Cognitive Linguistics 12.3: 211-245.

Quirk, Randolph et al. (1985) A Comprehensive Grammar Of The English Language. London: Longman.

Raimes, Ann (2002) Keys for Writers: A Brief Handbook. Boston: Houghton Mifflin.

Schiffrin, Deborah (1986) Functions of “and” in discourse. Journal of Pragmatics 10: 41-66.

Schiffrin, Deborah (1987) Discourse Markers. Cambridge: Cambridge University Press.

Schiffrin, Deborah (2006) Discourse marker research and theory: Revisiting and. In Kerstin Fischer (ed.), Approaches to Discourse Particles. Amsterdam: Elsevier, pp. 315-338.

Sotirova, Violeta (2004) Connectives in free indirect style: Continuity or shift? Language and Literature 13.3: $216-234$. 
Thompson, Geoff (2005) But me some buts: A multidimensional view of conjunction. Text 25.26: 763791.

Traugott, Elizabeth Closs (1986) On the origins of "and" and "but" connectives in English. Studies in Language 10.1: 137-150.

Umbach, Carla (2005) Contrast and information structure: A focus-based analysis of but. Linguistics 43.1: 207-232. 